\title{
ANALISA DAN PERANCANGAN INFRASTRUKTUR JARINGAN WIRELESS LOCAL AREA NETWORK (WLAN) PADA DINAS PERINDUSTRIAN DAN PERDAGANGAN KABUPATEN LOMBOK TENGAH
}

\author{
Didik Supriadi ${ }^{1}$, Hairul Fahmi ${ }^{2}$, Khairul Imtihan ${ }^{3}$ \\ 1,2Teknik Informatika, STMIK Lombok \\ ${ }^{3}$ Sistem Informasi, STMIK Lombok \\ Jln. Basuki Rahmat No.105 Praya Lombok Tengah 83511 \\ 1didariady16@yahoo.co.id_2iroel.ami@gmail.com ${ }^{3}$ khairulimtihan31@gmail.com
}

\begin{abstract}
The Office of Industry and Trade of Central Lombok Regency is one of the Government agencies in charge of improving services to the community in the field of industry and trade in a rule and continuously without differentiating between one another, so that the community is satisfied with the services provided by government agencies especially Department of Industry and Trade, Central Lombok Regency. The Office of Industry and Trade of Central Lombok Regency already has a Wireless network but does not reach all the existing rooms from ten work rooms, only four rooms can use it.

The research method that I use is NDLC method (Network Developmen Life Cycle) with phases, namely: analysis (analysis), design (design), prototype simulation (prototype simulation), implementation (monitoring), monitoring (observation), management (Settings). The author utilizes the client router mode on the Assespoint Wireless TP-Link WA5210G so that it can reach all the rooms in the Lombok Industry and Trade Office.

The results of this study concluded that the analysis is conducted using the method PIECES with this method the authors find that there are any problems or shortcomings discovered that there was still room of many rooms that have not gotten an existing network connection so I have to replace or mendisablekan wireless routers that already exist in District Office of Industry and Trade Attic with a new practical device that is Radio Outdoot with type or brand TP-Link WA5210G where this device has three nodes or functions and can withstand heat and reach up to one km depending on the height of the pole used. A wireless system with AP Client Router mode implemented has been successfully executed. The entire wireless system is tested by testing the client / user where the wireless client router device can work optimally to reach all rooms that cannot be reached by wireless that already exist in the industrial and trade department of Central Lombok district.
\end{abstract}

Keywords : Client Router, Wireless, Network Developmen Life Cycle.

\section{ABSTRAK}

Kantor Dinas Perindustrian dan Perdagangan Kabupaten Lombok Tengah merupakan salah satu instansi Pemerintah yang bertugas meningkatkan pelayanan kepada masyarakat dalam bidang industri dan perdagangan secara aturan dan terus menerus tanpa membedakan antara yang satu dengan yang lainnya, sehingga masyarakat merasa puas dengan pelayanan yang diberikan oleh instansi pemerintah khususnya Dinas Perindustrian dan Perdagangan Kabupaten Lombok Tengah. Dinas Perindustrian dan Perdagangan Kabupaten Lombok Tengah sudah memiliki jaringan Wireless namun tidak menjangkau semua ruangan yang ada dari sepuluh ruangan kerja hanya empat ruangan saja yang dapat memanfaatkan.

Metode penelitian yang penulis gunakan adalah metode NDLC (Network Developmen Life Cycle) dengan fase-fase, yaitu : analysis (analisis), design (perancangan), simulation prototipe (prototip simulasi), implementation (penerapan), monitoring (pengamatan), management, (pengaturan). Penulis memanfaatkan mode client router pada Assespoint Wireless TP-Link WA5210G sehingga dapat menjangkau semua ruangan yang ada Pada Dinas Perindustrian dan Perdagangan Kabupaten Lombok.

Hasil penelitian ini menyimpulkan bahwa analisis dilakukan dengan menggunakan metode PIECES dengan metode ini penulis menemukan ada beberapa masalah atau kelemahan yang ditemukan yaitu masih ada ruang dari sekian banyak ruangan yang belum mendapatkan koneksi jaringan yang ada sehingga penulis harus mengganti atau mendisablekan router wireless yang sudah ada pada Dinas Perindag Kab. Loteng dengan perangkat baru praktis yaitu Radio Outdoot dengan type atau merek TP-Link WA5210G dimana Perangkat ini memiliki tiga node atau fungsi dan tahan akan panas dan jangkauannya bisa sampai satu $\mathrm{km}$ tergantung tinggi dari tiang yang digunakan. Sistem wireless dengan mode AP Client Router yang diimplemetasikan telah berhasil dijalankan dengan baik. Keseluruhan sistem wireless di ujicoba dengan 
melakukan pengujian terhadap client/ user dimana perangkat wireless client router dapat bekerja secara optimal menjangkau seluruh ruangan yang belum dapat dijangkau oleh wireless yang sudah ada pada dinas perindustrian dan perdagangan kabupaten lombok tengah.

Kata Kunci : Client Router, Wireless, Network Developmen Life Cycle.

\section{Pendahuluan}

Kemajuan teknologi informasi pada saat ini terus berkembang seiring dengan kebutuhan manusia yang menginginkan kemudahan, kecepatan dan keakuratan dalam memperoleh informasi, oleh karena itu kemajuan teknologi informasi harus terus di upayakan dan ditingkatkan kualitas dan kuantitasnya. Salah satu kemajuan teknologi informasi di bidang transmisi pada saat ini yang berkembang selain fiber optic ialah penggunaan perangkat wireless LAN yang disingkat dengan WLAN adalah teknologi jaringan yang tidak menggunakan perangkat kabel sebagai media pengantar (transmisi) data yang umum dijumpai di dalam sebuah jaringan komputer dewasa ini, teknologi ini sesuai dengan namanya wireless yang artinya Jaringan tanpa kabel, memanfaatkan gelombang radio untuk melakukan interaksi atau komunikasi antar unit komputer. Pada dasarnya penggunaan WLAN pada suatu jaringan tidak berbeda dengan jaringan yang menggunakan kabel sebagai media transmisinya, hanya saja biaya pemasangan akan relatif lebih ringan.

Berdasarkan observasi yang penulis lakukan pada Dinas Perindustrian dan Perdagangan Kabupaten Lombok Tengah pemanfaatan jaringan wireless masih kurang, masih ada beberapa ruangan yang belum mendapat fasilitas internet, seperti pada ruang kabid industri, ruang kabid Perdagangan, ruang pengadaan barang, dan ruangan aula rapat, banyaknya permintaan akan akses internet dari para pegawai yang nantinya akan di pergunakan untuk hal positif yang akan mendukung kinerja para pegawai, akses internet sebelumnya hanya ada di beberapa ruangan seperti ruangan sekertariat, kepala dinas dan ruangan kasubbag umum dan kepegawaian, penulis disini akan memanfaatkan jaringan tanpa kabel atau yang dikenal dengan wireless atau wireless LAN, dalam pemanfaatan jaringan wireless bisa menggunakan sistem indoor atau outdoor. Jika dilakukan konfigurasi secara indoor akan membutuhkan sumber daya banyak sesuai dengan ruangan yang ada maka dari itu dimanfaatkan sebuah jaringan wireless bersifat outdoor menggunakan sebuah akses point outdoor dan dipancarkan kesegala arah.

Pada Dinas Perindustrian dan Perdagangan Kabupaten Lombok Tengah belum ada jaringan yang menjangkau atau mencakup seluruh area, atas dasar tersebut diatas penulis perlu melakukan perancangan jaringan WLAN menggunakan $A p$ wireless radio outdoor dengan adanya jaringan wireless atau hotspot ini dapat memudahkan para pegawai dalam mengakses jaringan internet, sehingga civitas Dinas Perindustrian dan Perdagangan Kabupaten Lombok Tengah mendapatkan pelayanan yang lebih baik dalam akses informasi.

\section{Tinjauan Pustaka}

Menurut Zawiyah Saharuna (2016), pada penelitiannya yang berjudul "Desain Jaringan Wireless Local Area Network Berdasarkan Cakupan Area dan Kapasitas" menjelaskan Desain jaringan WLAN berdasarkan cakupan area dan kapasitas pada kampus 2 PNUP menggunakan Access Point sebanyak 20 buah Access Point untuk JTE, 25 buah Access Point dan untuk JAK dan 25 buah untuk JAN. Desain Jaringan WLAN sebaiknya mempertimbangkan cakupan area dan kapasitas, karena desain yang mempertimbangkan cakupan area saja hanya dapat memenuhi 77\% kebutuhn Access Point.

Menurut Shinta Esabella (2016), pada penelitiannya yang berjudul "Perancangan Infrastruktur Jaringan Komputer untuk Mendukung Implementasi Sistem Informasi Pada Universitas Teknologi Sumbawa" menjelaskan dengan menggunakan metode Network Development Life Cycle (NDLC) dalam penelitian ini, mendapatkan hasil pengujian kinerja layanan berdasarkan parameter Quality of Service (QOS) pada kedua perancangan infrastruktur jaringan Komputer Universitas Teknologi Sumbawa, yakni perancangan dengan media kabel memiliki Page Response Time 82,3\% lebih cepat dibandingkan dengan menggunakan media Nirkabel, sedangakan objek Response Time media kabel juga 80,6 lebih cepat dibandingkan dengan menggunakan media Nirkabel, dan Delay pada media kabel lebih rendah $19.1 \%$ dari media Nirkabel.

Menurut Nur Kukuh Wicaksono (2016), pada penelitiannya yang berjudul "Analisis Quality of Service Jaringan Wireless LAN Pada PGRI Yogyakarta" menjelaskan pengukuran untuk jaringan Wireless LAN di Universitas PGRI Yogyakrata menggunakan metode QoS (Quality of Servece) dengan delay, Packet Loss, bandwidth, dan througput dimana pengukuran diukur selama 
sehari pada tiap lantai untuk tiap gedungnya. Dengan hasil delay untuk gedung $\mathrm{C}=120$ $m s$,gedung $\mathrm{B}=148 \mathrm{~ms}$ dan gedung $\mathrm{A}=196 \mathrm{~ms}$, hasilkan data gedung A performa delay jelek, dan untuk packet loss gedung B dan C mendapat performa yang bagus. Sedangkan untuk packet loss gedung $\mathrm{C}=35 \%$, gedung $\mathrm{B}=27 \%$, A sebesar $28 \%$ untuk throughput mendapatkan hasil gedung C, B, dan A yaitu : 23\%, 24\%, 20\%. Sehingga performa packet loss throughput menurut standar TIPHON masuk katagori jelek untuk bandwidth rata-rata bandwidth yaitu 195398 bit/s untuk gedung C dan B, gedung A rata-rata bandwidth yaitu 223426 bit/s dan $101744 \mathrm{bit} / \mathrm{s}$.

Menurut Royanul Fitron (2016), pada penelitiannya yang berjudul "Analisis Relibilitas Kinerja Jaringan Wireless LAN Menggunakan QoS Pada Perpustakaan Grahatama Pustaka Yogyakarta" menjelasakan bahwa Relibilitas kinerja jaringan WLAN (Wireless Local Area Network) pada Perpustakaan Grahatama Pustaka sangat baik ditunjukkan dengan nilai realibilitas mendekati $100 \%$, didukung dengan nilai ratarata tertinggi bandwidth transfer rate sebesar 205,1 Kbps yang terjadi di area gedung lantai 2 pada hari selasa, 9 mei 2016. Menurut versi TIPHON, parameter delay menunjukkan rata-rata nilai delay berkisar $150 \mathrm{~ms}-300 \mathrm{~ms}$ yang terjadi pada area gedung lantai 1 dan gedung lantai 2 termasuk dalam katagori bagus. Sedangkan pada parameter packet loss pada area gedung lantai 1 dan gedung lantai 2 juga dalam katagori degradasi bagus yaitu dengan nilai packet lossnya berkisar $15 \%$.

\section{Metodologi Penelitian}

\subsection{Metode Pengumpulan data}

Pada metode ini penulis terjun langkung ke lokasi penelitian yaitu pada dinas perindustrian dan perdagangan kabupaten lombok tengah melihat secara langsung perangkat jaringan yang digunakan, seperti apa jaringannya, topologi yang digunakan, melakukan wawancara dengan beberapa pegawai yang ada membahas terkait jaringannya, ada yang mengatakan jaringannya dari segi kecepatan (speed) lumayan, namun sinyal jaringannya tidak dapat mencakup semua ruangan.

\subsection{Metode Perancangan}

Pada tahap ini penulis menggunakan metode Network Development Life Cycle (NDLC) untuk jelasnya penulis jelaskan dibawah ini tahapannya :

Pada tahap analisis penulis menganalisa kelemahan atau kekurang dari jaringan yang sedang berjalan, apa saja perangkat yang digunakan, dan apa solusi atau apa saya perangkat yang dibutuhkan untuk memperbaiki atau meningkatkan kinerja dari jaringannya, pada dinas ini topologi yang digunakan masih sangat minim topologinya dari provider langsung ke modem bawaan telkom lalu router dengan mode asses point.

Pada tahap perancangan ini dari permasalahan yang penulis uraikan diatas penulis membuatkan solusi dari permasalahannya yaitu dengan menambahkan sebuah asses point namun kali ini sebuah asses point yang sifatnya outdoor dimana nantinya penulis akan mengkonfigurasi perangkat dengan mode AP Client Router.

Pada tahap simulasi ini penulis tidak merubah atau mengganggu jaringan yang sedang berjalan namun penulis menambahkan sebuah perangkat asess point dengan tipe TP-Link WA5210G dimana penulis menggunakan Mode Client Router yang fungsinya adalah menembak dan menyebarkan sinyal yang jaringan yang sedang berjalan.

Pada tahap implementasi, penulis melakukan uji jangkauan sinyal, penulis menggunakan sebuah perangkat lunak WirelessMoon dimana dengan sofware ini dapat mengetahui jarak jangkauan dan berapa dbm yang didapatkan.

Monitoring pada tahap ini penulis belum melakukannya karena penulis masih dalam tahap perancangan tetapi penulis sudah mengimplementasikannya.

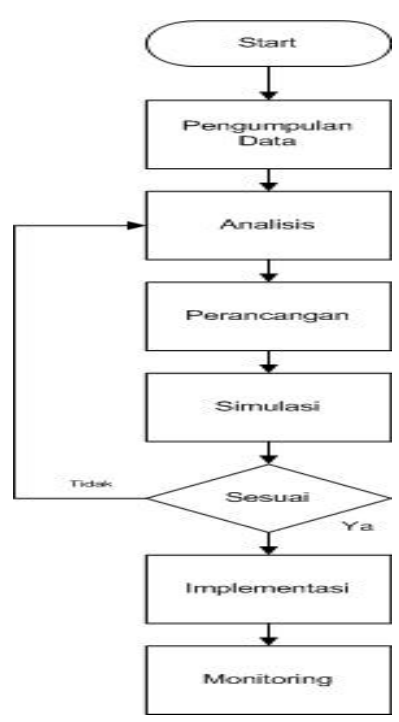

Gambar 3.1 Flowchart Metodologi Penelitian.

\subsection{Metode Analisis}

Pada tahap ini penulis menggunakan metode PIECES dimana pada tahap ini memiliki beberapa tahapan dari segi Performa, 
Informasi,Ekonomic, Control, Efesiency dan Service yang ini dapat dilihat hasilnya pada pembahsan 4 hasil dan pembahasan.

\section{Hasil dan Pembahasan}

\subsection{Hasil Analisis}

Berdasarkan analisis yang dilakukan dengan metode Pieces penulis dapat menyimpulkan hasil dibawah ini :

Tabel 4.1 Hasil analisis

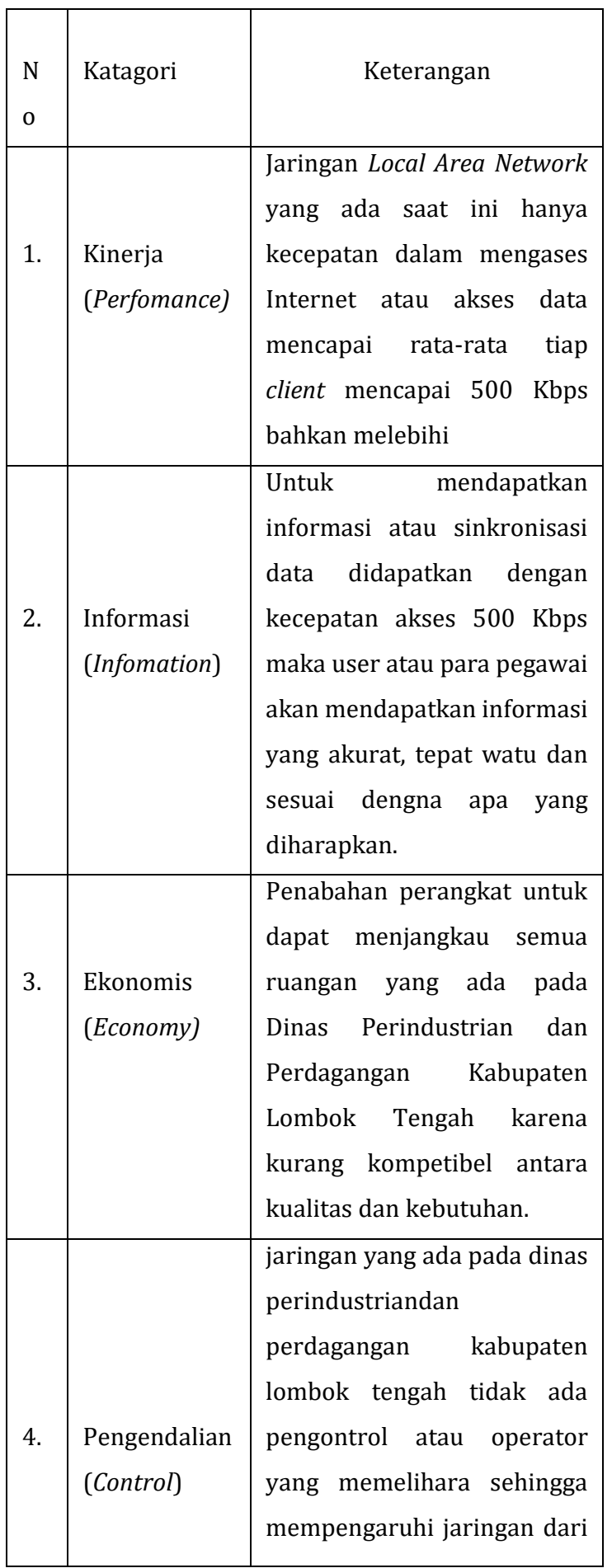

\begin{tabular}{|l|l|lr|}
\hline & & $\begin{array}{l}\text { segi ketepatan } \\
\text { kemudahan akses dan } \\
\text { ketelitian data yang } \\
\text { diperoses. }\end{array}$ \\
\hline 5. & $\begin{array}{l}\text { Dengan adanya jaringan } \\
\text { pada Dinas Perindustrian } \\
\text { dan Perdagangan Kabupaten } \\
\text { Lombok Tengah para } \\
\text { pegawai dapat bekerja } \\
\text { dengan baik. }\end{array}$ \\
\hline 6fisien & $\begin{array}{l}\text { Dengan adanya jaringan } \\
\text { (Efficiency) }\end{array}$ \\
\hline $\begin{array}{l}\text { Pelayananan mempermudah para } \\
\text { (Service) }\end{array}$ & $\begin{array}{l}\text { pegawai didalam } \\
\text { menjalankan tugas dan } \\
\text { tanggung jawab }\end{array}$ \\
\hline
\end{tabular}

\subsection{Hasil Analisis Kekuatan Jangkauan Sinyal Sebelumnya}

Pada analisis kekuatan jangkauan sinyal yang penulis lakukan pada ruangan kabid perdagangan dengan jarak 20 meter dengan halangan tembok satu jengkal sinyal yang didapatkan sangat lemah bahkan sidak mendapatkan sinyal Penulis menganalisis dengan Sofware WirelessMoon bisa dilihat pada gambar dibawah ini :

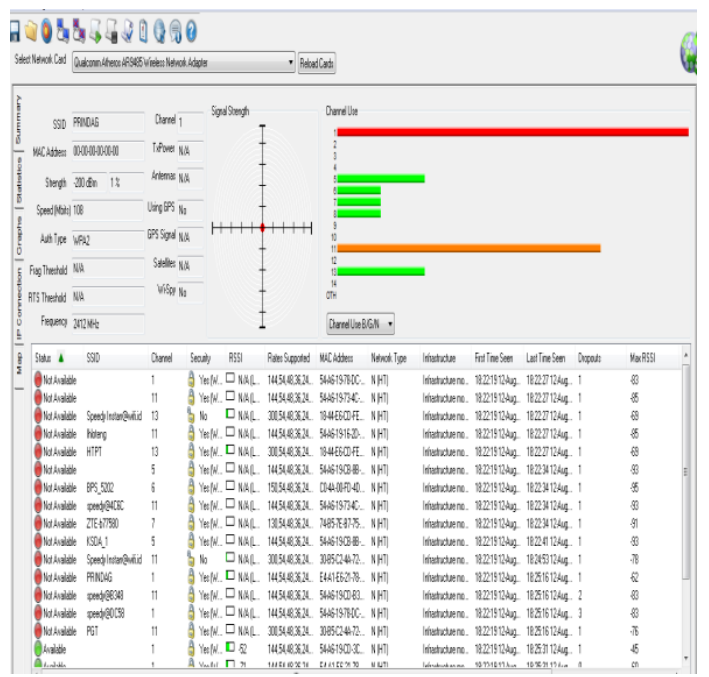

Gambar 4.1 Kekuatan Sinyal Sebelumnya. 


\subsection{Topologi Jaringan yang sedang berjalan}

Jaringan komputer yang sedang berjalan pada kantor dinas perindustrian dan perdagangan kabupaten lombok tengah User terkoneksi atau terhubung terpusat pada sebuah terminal (asses point) dengan topologi ini jaringannya masih terdapat kelemahan, tidak dapat menjangkau semua ruangan kerja pegawai yang ada.

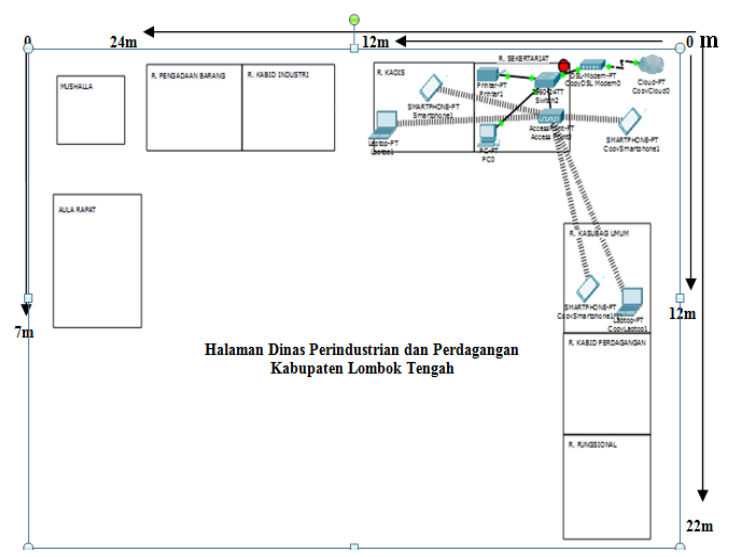

Gambar 4.2 Topologi jaringan yang sedang berjalan.

\subsection{Topologi Perancangan Jaringan}

Topologi ini penulis menambahkan sebuah perangkat dengan type TP-Link WA5210G dimana penulis mengkonfigurasi dengan mode $A P$ Client Router dengan fungsi menembak dan memancarkan sinyal jaringan.

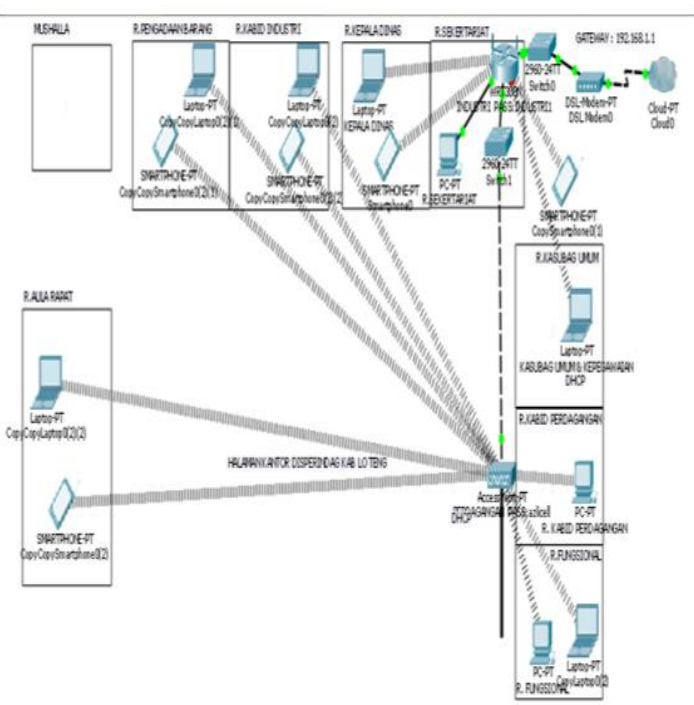

Gambar 4.3 Topologi perancangan Jaringan.

\subsection{Hasil Analisis Kekuatan Jangkauan sinyal Sesudahnya}

1. Hasi Uji Jangkauan Sinyal Koneksi Pada Ruangan Kepala Bidang Perdagangan dengan

ISSN. 2620-6900 (Online) 2620-6897 (Cetak) jarak 20 meter dengan testspeed mencapai 200300 Kbps menggunakan Sofware WirelessMoon.

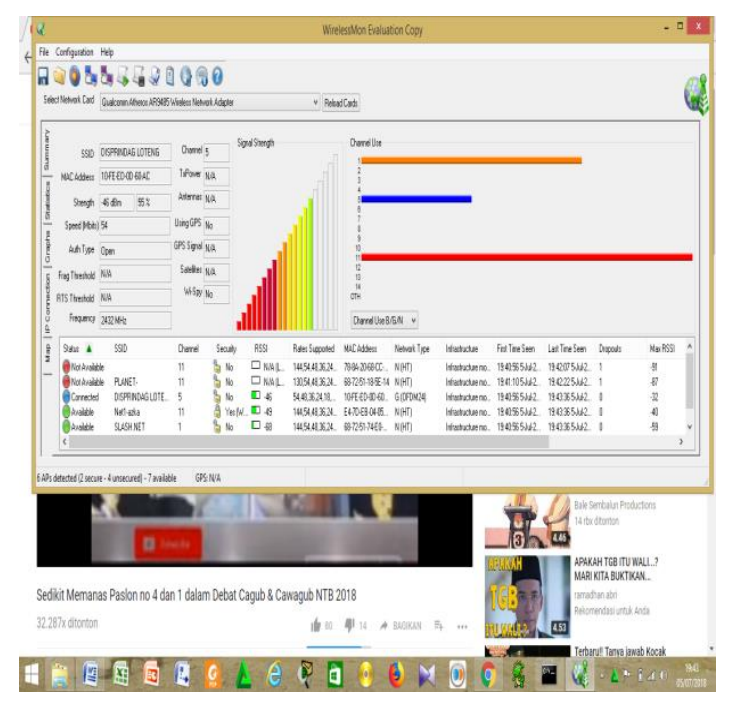

Gambar 4.4 Uji Jangkauan Sinyal Koneksi Pada Ruangan Kepala Bidang Perdagangan.

2. Hasi Uji Jangkauan Sinyal Koneksi Pada Ruangan Kepala Bidang Industri dengan jarak 16 meter dengan testspeed mencapai 200-300 Kbps menggunakan Sofware WirelessMoon.

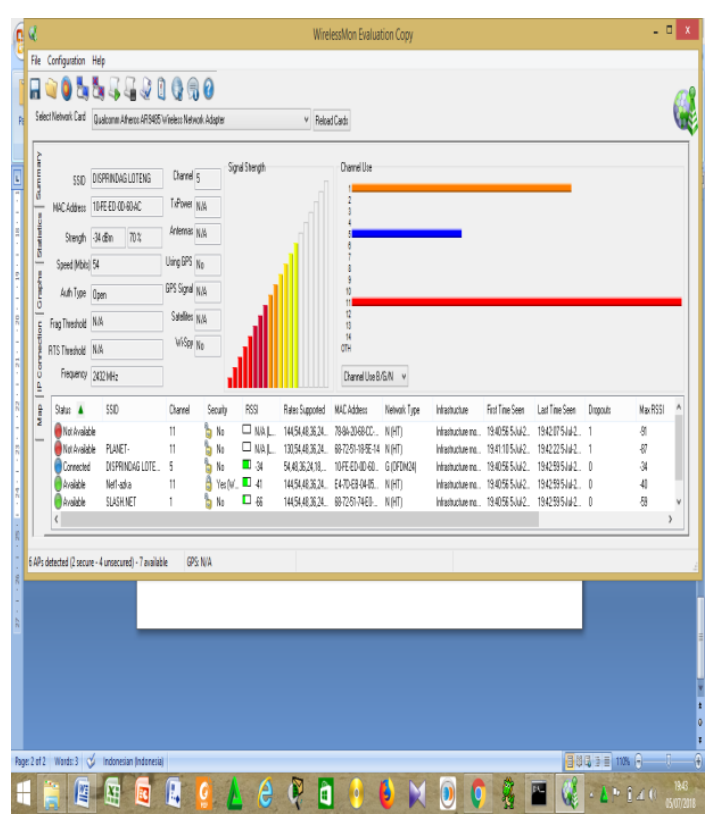

Gambar 4.9 Hasi Uji Koneksi Pada Ruangan Kepala Bidang Industri.

3. Hasi Uji Jangkauan Sinyal Koneksi Pada Ruangan Pengadaan Barang dengan jarak 20 meter dengan testspeed mencapai 200 Kbps menggunakan Sofware WirelessMoon. 


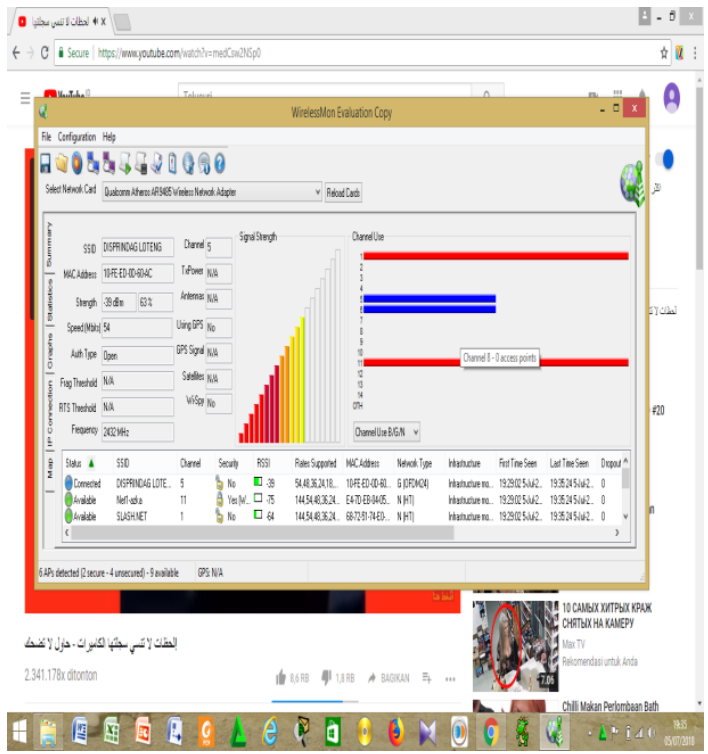

Gambar 4.10 Hasi Uji Koneksi Pada Ruangan Pengadaan Barang.

\section{Kesimpulan dan Saran \\ 5.1 Kesimpulan}

Dari uraian pada bab-bab yang telah dibahas sebelumnya penulis mendapatkan beberapa kesimpulan sebagai berikut :

1. Dengan penambahan sebuah perangkat yang disetting dengan mode Ap Client Router Dinas Perindustrian dan Perdagangan Kabupaten Lombok Tengah dapat terkaper semua area yang ada.

2. Kecepatan atau kesetabilan transfer data sesudah penambahan perangkat wireless WA5210G dengan Mode Ap Client Router lebih mudah dan lebih meningkatkan kinerja jaringan.

\subsection{Kesimpulan}

1. Untuk peneliti selanjunya, diperlukan perancangan sistem informasi yang berkaitan dengan identitas dan kedisiplinan para pegawai . 2. Penelitian selanjutnya, dibutuhkan Peningkatan kinerja dan keamanan jaringan karena jaringannya bersifat loss, Sistem wireless client router ini belum ada fitur autentifikasi sendiri untuk memberikan username dan fassword karena harus mengikuti username dan fasswor yang akan disebarkan sinyalnya.

3. Dibutuhkan seorang administrator jaringan yang bertugas didalam mengontrol sistem yang berkaitan dengan jaringan yang ada.

\section{Daftar Pustaka}

Saharuna, Zawiyah (2016) "Desain Jaringan Wireless Local Area Network Berdasarkan Cakupan Area dan Kapasitas".

Esabella, Shinta (2016) "Perancangan Infrastruktur Jaringan Komputer untuk Mendukung Implementasi Sistem Informasi Pada Universitas Teknologi Sumbawa".

Nur Kukuh Wicaksono (2016) "Analisis Quality of Service Jaringan Wireless LAN Pada PGRI Yogyakarta".

Fitron, Royanul (2016) "Analisis Relibilitas Kinerja Jaringan Wireless LAN Menggunakan QoS Pada Perpustakaan Grahatama Pustaka Yogyakarta".

Fadillah Usman (2015) “ Analisa Kinerja Jaringan Wireless Local Area Network Menggunakan QoS Dan RMA Pada Perpustakaan Gadjah Mada"

Febrianto, T. (2015) “Analisis Manajemen Local Area Network (Lan)(Studi Pada Bank X). Jurnal Administrasi Bisnis" 19(1).

Manru, E. P. (2015) "Analisa Kinerja Jaringan WLAN Pada Perangkat Access Point 802.11/g" (Studi Kasus Fakultas Teknik Universitas Riau). Jurnal Online Mahasiswa (JOM) Bidang Teknik dan Sains, 3(1), 1-11.

Gunarjo, K. (2016) "Perancangan Dan Implementasi Jaringan Wireless Local Area Network (Wlan) Antar Gedung Di Smk Muhammadiyah Imogiri. Prodi. Teknik Informatika, Fakultas Teknik Universitas PGRI Yogyakarta".

Novrianda, R. (2017) "Rancang Bangun Keamanan Jaringan Wireless Pada Stiper Sriwigama Palembang Dengan Radius Server". Jurnal Maklumatika, 4(1). 